\title{
Health and welfare assessment of working donkeys in and around Rama town, Tigray, Ethiopia
}

\author{
Shushay Fsahaye, Niraj Kumar, Etsay Kebede* and Nigussie Abebe \\ College of Veterinary Medicine, Mekelle University, P.O. Box 1398, Mekelle, Ethiopia \\ * Corresponding author: email: etsaykebede@yahoo.com
}

\begin{abstract}
A cross-sectional study was conducted from November 2016 to April 2017 with the objectives to assess the major health problems and associated factors compromising welfare and health of working donkeys in and around Rama Town, Mereb Lake District, Central zone of Tigray Regional state Ethiopia. Both direct observational (animal based) and indirect (owner based) interviews were used to collect data. A total of 384 randomly selected working donkeys were examined and 120 donkey owners were interviewed. From these $27.1 \%, 45.3 \%$, $9.9 \%, 22.9 \%, 17.2 \%$ and $41.7 \%$ donkeys were suffering from skin coat, wound, musculo-skeletal, parasitic, ocular and behavioral problems, respectively. The occurrence of wound varied significantly $(p<0.05)$ among age categories and higher prevalence was noticed in donkeys more than 15 years of age (85.7\%). The body condition score, duration of work and average weight loaded were also having significant $(p<0.05)$ effect on wound prevalence. The findings of indirect assessment revealed that majority $(96.7 \%)$ of the respondents in the study area had no knowledge and information on donkey welfare. Financial problems and high cost of drugs were the major constraints recorded in this study. The findings of present study indicated that welfare problems are highly prevalent in the working donkeys in the study area.
\end{abstract}

Keywords: Donkey; Ethiopia; Rama district; Welfare; Wound

\section{Introduction}

Ethiopia has about 7.4 million donkeys among which about 4.58 million are used for transportation whereas about 0.83 million and 0.27 million are used for draught and other purposes, respectively (CSA, 2014/15). Although working donkeys are found in all the ecological zones of the country (arid to mountain), the majority are found in the highlands and are primarily used as pack animals. The low level of development of the road transport network and the 
rough terrain of the country makes the donkey the most valuable pack animal under the smallholder farming systems of Ethiopia (Gbrewold et al., 1997). Despite the increase in mechanization throughout the world, working donkeys are still well deserving of the name 'beasts of burden' in many developing countries. They have an important role to play in transport of people and goods in arid and semi-arid areas where roads are poor or non-existent.

Working donkeys often are involved in more multipurpose activities than horses. They transport goods to and from markets, farms, and shops, travelling long distances. They also pull carts carrying heavy loads. They work from 4 to 12 hours/day, depending on the season and type of work. Unlike horses, working donkeys are not provided with sufficient feed supplements. Feed shortage and disease are the major constraints to productivity and work performance of equines. The welfare issues of donkeys are compromised by resource poor farmers in terms of overloading, overwork and inadequate access to feed or health care facilities. The increasing human population, demands for transport of goods to and from far, remote areas, and construction activities around towns are making donkeys highly demanded animals (Biffa and Woldemeskel, 2006).

Animals are "sentient beings" that experience states such as pain, suffering and satisfaction. Avoidance of management of pain and anguish in animals are commonly considered as ethical necessities in scientific researches and teaching. Hence, animal welfare entails appropriate disease prevention and veterinary care, suitable management, nourishment and gentle handling (Bekele et $a l ., 2013)$. Despite their use, the husbandry practices of working donkeys are poor. Some hobbling methods cause discomfort and impose ophthalmic problems (Mekuria et al., 2013). Therefore, the objective of the study was health and welfare assessment and associated risk factors of working donkeys in the study area.

\section{Materials and methods}

\section{Study area}

The study was conducted from November 2016 to April 2017 in and around Rama town, the administrative centre of Mereb Lake wereda in Tigray region in the semiarid highland of northern Ethiopia. It is one of the operational areas of the International Donkey Sanctuary Trust (IDST). Rama town is situated in Central zone of Tigray, located $258 \mathrm{~km}$ north west of Mekelle city $35 \mathrm{~km}$ 
north of the town of Adwa and $7 \mathrm{~km}$ from the border with Eritrea. This town occupies a fertile lowland area and located at latitude of $14^{\circ} 25^{\prime} \mathrm{N}$ and longitude of $38^{\circ} 47^{\prime} \mathrm{E}$ with an elevation of 1385 meters above sea level. The wereda has annual rain fall of $600-1200 \mathrm{~mm}$ and average annual temperature of $33.3^{\circ} \mathrm{C}$. The climate of the study area is tropical and semi-arid.

\section{Study animals}

The study was conducted on indigenous breed of working Abyssinian donkeys which plays major role in the area. Both sex and all age groups of working donkeys were included in the study.

\section{Data collection}

\section{Physical assessment}

Direct physical examination of working donkeys was done to assess welfare and physical status of the working donkeys. A total of 384 working donkeys were used for direct welfare assessment. The conditions that were assessed include sex, age, body condition score, skin problem, parasite, musculoskeletal problem, eye, dental and mucus membrane abnormality, wound, behaviour of the donkeys and other health problems. The data were collected using data collection format. Body condition score (BCS) of the donkey was estimated and scored in the range of 1 to 5 . However, for the purpose of data analysis it was categorized in three major categories, Poor (BCS1-2), Moderate (BCS24), Good (BCS>4) (NAWC, 2005). Age of the animal was determined by dentition and it was categorized into five groups; $<2.5$ years, $2.5-5$ years, $6-10$ years, 11-15 years and $>15$ years old (Crane, 1997).

\section{Questionnaire survey}

Indirect assessment was conducted by using semi-structured questionnaire to study the welfare of working donkeys. The questionnaire was administered for 120 respondents (donkey owner).

\section{Sample size and sampling method}

Sample size required for the study was calculated based on the formula given by Thrusfield (2005). Simple random sampling method was applied. In this study $50 \%$ prevalence with $5 \%$ desired level of precision and $95 \%$ of confidence levels was used to calculate the sample size using the following formula. 
$\mathrm{N}=\frac{1.96}{\mathrm{~d}^{2}} \frac{{ }^{*} \text { Pexp. (1-Pexp.) }}{\mathrm{d}^{2}}$

Where:

$\mathrm{N}=$ the required sample size

$1.96^{2}=$ the value of $Z$ at $95 \%$ confidence level

Pexp= Expected prevalence $(=50 \%)$

$\mathrm{D}=$ Desired absolute precision level at $95 \%$ confidence interval $(=0.05)$

Accordingly, a total of 384 donkeys were sampled from the study area.

\section{Data analysis}

The collected data from direct physical examination and questionnaire survey were entered into a Microsoft Excel Spread sheet and analysed with statistical package for the social science (SPSS) version 20 software. Descriptive and analytic statistics were used and Chi-square test $\left(x^{2}\right)$ was computed to see the association of risk factors with the target variables of interest. A p-value less than 0.05 was considered significant.

\section{Results}

From 384 donkeys accessed for direct welfare, $69.3 \%$ were male with different age groups. Majority of them were in poor body condition (43\%) followed by good (29.7\%) and medium (27.3\%) body condition. Descriptive statistics for sex, age and body condition score of the sampled donkeys are illustrated in Figure 1. 


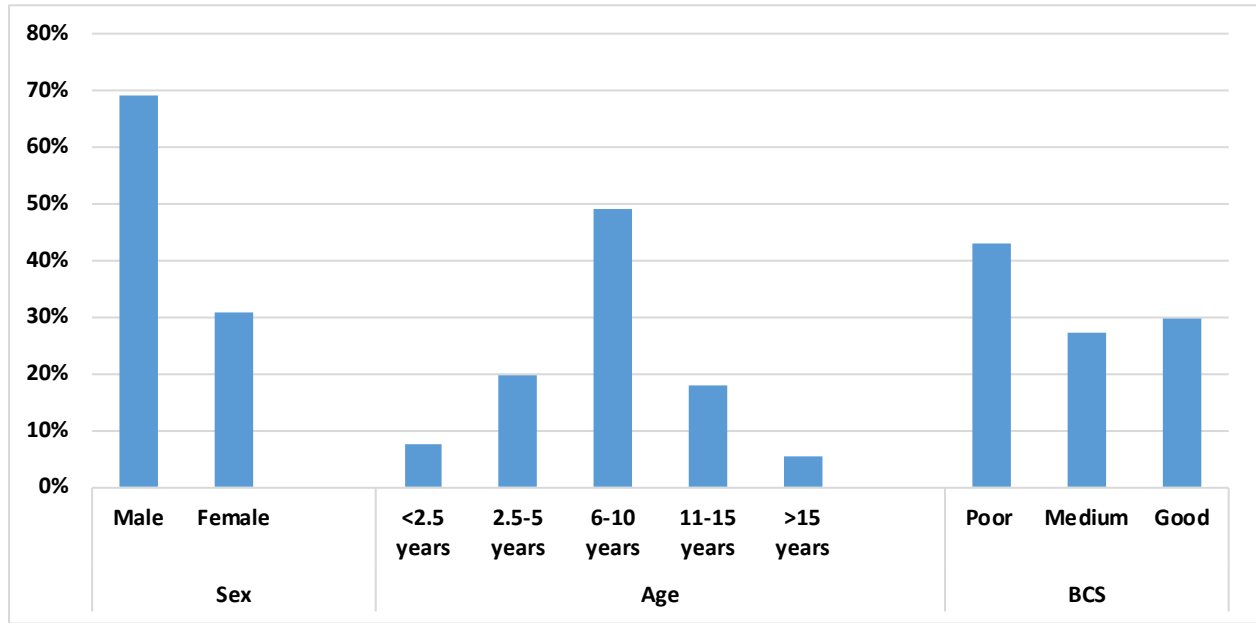

Figure 1.Descriptive statistics for sex, age and body condition score of physically examined donkeys to $(\mathrm{N}=384)$

Results on health condition of working donkeys are shown in Table 1. Overall prevalence of wound was recorded to be $45.3 \%$. Brand/burn sore, back sore and harness sore were the major wound types observed in the working donkeys. Overall prevalence of problems related to skin coat, musculoskeletal, parasitic and eye were $27.1 \%, 9.9 \%, 22.9 \%$ and $17.2 \%$, respectively. Among skin problems, loss of elasticity (15.9\%) was the major problem observed followed by alopecia, habronemiasis and sarcoid. Lameness was recorded in $4.4 \%$ of working donkeys. Gastrophilus (16.4\%) and ticks (6.5\%) were the major parasitic problems observed in this study. 
Table 1. Health condition of working donkeys in the study area( $\mathrm{N}=384)$.

\begin{tabular}{|c|c|c|c|c|}
\hline Туре & $\begin{array}{l}\text { Major health } \\
\text { problems }\end{array}$ & Frequency & Percent (\%) & $\begin{array}{c}\text { Overall } \\
\text { Prevalence (\%) }\end{array}$ \\
\hline Skin Coat & $\begin{array}{l}\text { Alopecia } \\
\text { Loss of elasticity } \\
\text { Sarcoid } \\
\text { Habronemiasis }\end{array}$ & $\begin{array}{c}25 \\
61 \\
8 \\
10\end{array}$ & $\begin{array}{c}6.5 \\
15.9 \\
2.1 \\
2.6\end{array}$ & $104(27.1 \%)$ \\
\hline Type of wound & $\begin{array}{l}\text { Back sore } \\
\text { Harness sore } \\
\text { Brand/burn sore } \\
\text { Bite sore } \\
\text { Other injuries }\end{array}$ & $\begin{array}{l}45 \\
33 \\
55 \\
22 \\
19\end{array}$ & $\begin{array}{c}11.7 \\
8.6 \\
14.3 \\
5.8 \\
4.9\end{array}$ & $174(45.3 \%)$ \\
\hline $\begin{array}{l}\text { Musculoskeletal } \\
\text { problems }\end{array}$ & $\begin{array}{l}\text { Fracture } \\
\text { Lameness } \\
\text { Swollen joints } \\
\text { Hooves overgrowth }\end{array}$ & $\begin{array}{c}0 \\
17 \\
12 \\
9\end{array}$ & $\begin{array}{l}0.0 \\
4.4 \\
3.1 \\
2.4\end{array}$ & $38(9.9 \%)$ \\
\hline $\begin{array}{l}\text { Parasitic } \\
\text { problems }\end{array}$ & $\begin{array}{l}\text { Ticks } \\
\text { Lice } \\
\text { Gastrophilus eggs }\end{array}$ & $\begin{array}{c}25 \\
0 \\
63\end{array}$ & $\begin{array}{c}6.5 \\
0.0 \\
16.4\end{array}$ & $88(22.9 \%)$ \\
\hline Eye problem & $\begin{array}{l}\text { Lacrimation } \\
\text { Loss of vision (one } \\
\text { eye) } \\
\text { Inflammation }\end{array}$ & $\begin{array}{l}31 \\
12 \\
23\end{array}$ & $\begin{array}{l}8.1 \\
3.1 \\
6.0\end{array}$ & $66(17.2 \%)$ \\
\hline $\begin{array}{l}\text { Mucous } \\
\text { membrane }\end{array}$ & $\begin{array}{l}\text { Pale } \\
\text { Congested }\end{array}$ & $\begin{array}{l}26 \\
13\end{array}$ & $\begin{array}{l}6.7 \\
3.4\end{array}$ & $39(10.1 \%)$ \\
\hline $\begin{array}{l}\text { Behavioral } \\
\text { observation }\end{array}$ & $\begin{array}{l}\text { Hyper-esthetic } \\
\text { Depressed }\end{array}$ & $\begin{array}{c}27 \\
133\end{array}$ & $\begin{array}{c}7.1 \\
34.6\end{array}$ & $160(41.7 \%)$ \\
\hline Other diseases & $\begin{array}{l}\text { Digestive problem } \\
\text { Respiratory } \\
\text { problem }\end{array}$ & $\begin{array}{l}19 \\
38\end{array}$ & $\begin{array}{l}4.9 \\
9.9\end{array}$ & $57(14.8 \%)$ \\
\hline Dental condition & $\begin{array}{l}\text { Incisor teeth } \\
\text { problem } \\
\text { Cheek teeth } \\
\text { problem }\end{array}$ & $\begin{array}{l}12 \\
13\end{array}$ & $\begin{array}{l}3.1 \\
3.4\end{array}$ & $25(6.5 \%)$ \\
\hline
\end{tabular}

Lacrimation (8.1\%) and eye inflammation (6.0\%) were also recorded. Around $34.6 \%$ donkeys were observed to be depressed while $9.9 \%$ and $4.9 \%$ were observed for respiratory and digestive problems. Overall prevalence of dental problems was observed in $6.5 \%$ of donkeys (Table 1).

Prevalence of wound based on work type, sex, BCS, age, duration of work and load are shown in Table2. Prevalence of wound was higher in donkeys used for draught purpose(49.5\%) than those working forpack and other purposes, but no significant difference was observed on overall wound prevalence among 
work type $(p>0.05)$. Females were more prone to wound prevalence than male but the difference in the prevalence of wound among sex was not significant $(p>0.05)$.

Table 2. Prevalence of wound based on work type, sex, BCS, age, duration of work and load $(\mathrm{N}=384)$

\begin{tabular}{|c|c|c|c|c|c|}
\hline Variable & $\begin{array}{l}\text { Number } \\
\text { examined }\end{array}$ & $\begin{array}{l}\text { Number } \\
\text { affected }\end{array}$ & $\begin{array}{l}\text { Prevalence } \\
(\%)\end{array}$ & $x^{2}$ & P-value \\
\hline \multicolumn{6}{|l|}{ Work type } \\
\hline Draught & 212 & 105 & 49.5 & \multirow{3}{*}{1.1} & \multirow{3}{*}{0.396} \\
\hline Pack & 151 & 60 & 39.7 & & \\
\hline Other & 21 & 9 & 42.8 & & \\
\hline \multicolumn{6}{|l|}{ Sex } \\
\hline Male & 266 & 116 & 43.6 & \multirow[t]{2}{*}{1.3} & \multirow[t]{2}{*}{0.371} \\
\hline Female & 118 & 58 & 49.1 & & \\
\hline \multicolumn{6}{|l|}{ BCS } \\
\hline Poor & 165 & 99 & 60.0 & \multirow{3}{*}{11.5} & \multirow{3}{*}{0.010} \\
\hline Medium & 105 & 40 & 38.1 & & \\
\hline Good & 114 & 35 & 30.7 & & \\
\hline \multicolumn{6}{|l|}{ Age (year) } \\
\hline Under $<2.5$ years & 29 & 13 & 44.8 & \multirow{5}{*}{13.2} & \multirow{5}{*}{0.008} \\
\hline 2.5-5 years & 76 & 32 & 42.1 & & \\
\hline $6-10$ years & 189 & 64 & 33.9 & & \\
\hline $11-15$ years & 69 & 47 & 68.1 & & \\
\hline$>15$ years & 21 & 18 & 85.7 & & \\
\hline \multicolumn{6}{|c|}{ Duration on work (hour) } \\
\hline$<4$ & 131 & 34 & 25.9 & \multirow[t]{3}{*}{19.2} & \multirow[t]{3}{*}{0.000} \\
\hline $4-8$ & 174 & 81 & 46.5 & & \\
\hline$>8$ & 79 & 59 & 74.7 & & \\
\hline \multicolumn{6}{|c|}{ Avg. weight loaded (kg) } \\
\hline$<50$ & 108 & 39 & 36.1 & \multirow{3}{*}{10.7} & \multirow{3}{*}{0.015} \\
\hline $50-80$ & 169 & 62 & 36.7 & & \\
\hline$>80$ & 107 & 73 & 68.2 & & \\
\hline
\end{tabular}

There was significant difference in the prevalence of wound $(p<0.05)$ among different body condition scores. Donkeys with poor condition score were having highest prevalence (60\%) of wound followed by those with medium and good body condition. The present study also revealed that the occurrence of wound significantly differs $(p<0.05)$ with respect to the age of the donkey. Highest wound prevalence was observed in donkeys with age more than $15(85.7 \%)$ years and $11-15$ years $(68.1 \%)$ than those in the younger age group (Table 2).

The result also showed a significant association $(p<0.05)$ between the duration of work and the prevalence of wound. High wound prevalence was observed 
in donkeys working for more than 8 hours than those working less. There is also significant association $(p<0.05)$ between prevalence of wound and average weight loaded. The donkeys that carried weight greater than $80 \mathrm{~kg}$ had higher prevalence of wound (68.2\%) than those carrying less weight (Table 2).

Among the respondents interviewed in the current study, most of them (96.7\%) had no knowledge and information about donkey welfare. Vaccination (17.5\%) for anthrax and African horse sickness as well as deworming (21.7\%) was also practiced by farmers. Sick donkeys were treated mostly in veterinary clinics $(35.0 \%)$ and by traditional healers (40.8\%). Financial problems (44.2\%) and unavailability and high price of drug (35.8\%) were the major constraints stated by the farmers (Figure 2).

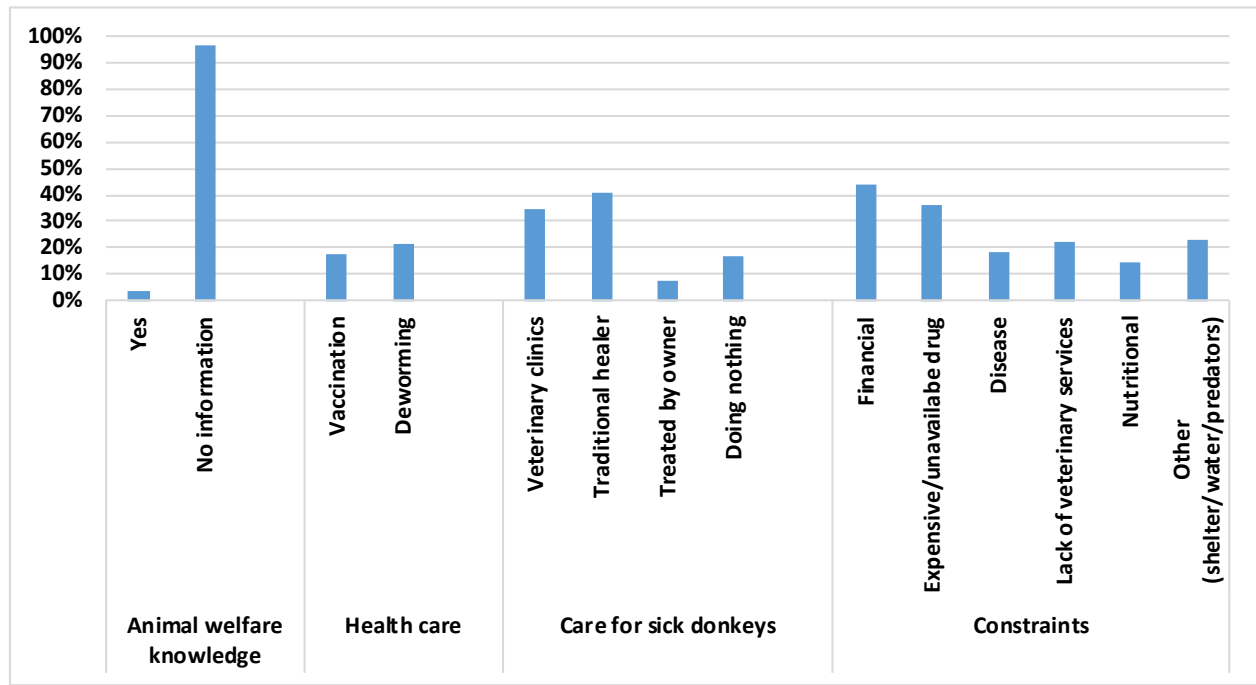

Figure 2. Distribution of respondent's knowledge, management and constraints $(\mathrm{N}=120)$

\section{Discussion}

The prevalence of dermatological conditions such as alopecia, loss of elasticity, sarcoid and habronemiasis were common among working donkeys in the study area. The overall prevalence of dermatological conditions was $27.1 \%$, which is higher than the findings of Tesfaye et al (2016) in Mirab Abaya District, Southern Ethiopia (25.8\%), Sameeh et al (2014) in Jordan (22.7\%), Her- 
ago et al (2015) in Wolaita Soddo Zuria district in southern Ethiopia (12.6\%) an d Ahmed et al (2010) in Pakistan (11\%). Kumar et al (2014) reported higher prevalence of skin problem (30.2\%) in working donkeys in Mekelle city of Ethiopia. Musculoskeletal, parasitic and eye problem were also observed in the study area which are more or less in line with the findings of Tesfaye et al (2016), Herago et al (2015) and Kumar et al (2014) in the different parts of Ethiopia. Mekuria and Abebe(2010) also reported higher prevalence of ectoparasites in donkeys than horses. Majority of the donkeys showed poor body condition (43.0\%) in the current study. Low body condition score was also reported by many researchers in different parts of Ethiopia (Burn et al., 2010; Morkaet al., 2014; Kumar et al., 2014). The prevalence of these conditions are associated with owner's poor knowledge of health care, poor veterinary and extension services, poor feeding and overall management (Biswas et al., 2013; Tesfaye et al., 2016).

The overall prevalence of wound in working donkeys in the present study was $45.3 \%$ which was higher than the $40 \%$ reported in Central Ethiopia (Pearson et al., 2002). In contrast, a higher prevalence was reported by Curran et al (2005) in Ethiopia (79.4\%), Biffa and Woldemeskel(2006) in Ethiopia (77.5\%), Tesfaye et al (2016) in Mirab Abaya District if southern Ethiopia (59.7\%), Herago et al. (2015) in Wolaita Soddo Zuria District of southern Ethiopia (58.6\%) and Burn et al (2007) in Jordan (59\%). Harness sore, back sore, brand or burn sore and bite sore were the major sore identified in the current study. The occurrence of these types of wounds in donkeys was also reported in many studies (Pritchard et al., 2005; Kumar et al., 2014). The causes of these wounds are basically related with animal welfare problems like improper harnessing, overloading and overworking of the donkeys (Kumar et al., 2014). Morgan (2008) reported different causes of wound in rural and urban areas. In rural areas, the cause of wound are primarily due to hyena or donkey bites whereas in urban areas it was due to road traffic accidents. Ill-fitting and improperly made tail straps with sharp edge causes lesions on the underneath of the base of tail of working donkeys. Poorly designed and ill fitted harnesses reduce the working efficiency due to discomfort and animals get fatigue (Pearson et al., 2003). It also increases the risk of injuries at the withers, back region and underneath the base of the tail due to friction (Kumar et al., 2014). Painful harness lesion may lead to secondary infections which will reduce the work capacity and longevity of the donkey (Smith, 2014). Branding or burn lesions is caused either by the owner burn-marking the animal or by traditional medical treatments (Burn et al., 2010). 
Behavioral problems like hyperesthesia and depression in working donkeys was also reported by many researchers over different parts of the world (Burn et al., 2010; Morka et al., 2014; Kumar et al., 2014). Morka et al (2014) reported 23.1\% in and Around Nekemte Town, while Pritchard et al (2005) reported $11.5 \%$ of the donkeys were depressed in their studies. Beating donkeys is one of the major causes of behavioral problem. Beating a donkey does not only cause wounds and physical pain but it also induces fear and severe stress to the animal (Rushen et al., 1999; Swann, 2006).

The present study shows that the prevalence of wound in working donkeys were non-significantly related with the type of work and sex which is in line with the findings of Tesfaye et al (2016). In contrary, Herago et al (2015) reported donkeys used for draught purpose had a significantly higher prevalence of wound than those used for pack and other purposes. Rugged landscape, uneven roads, overload, overwork and improper harness are the most plausible explanation for the variation in findings.

Donkeys with poor body condition were found to develop wound than those having good body condition $(p<0.05)$ in the current study which is in agreement with the findings of Herago et al.(2015) in Wolaita Soddo Zuria District of southern Ethiopia; Kumar et al (2014) in Mekelle City of Ethiopia; Mekuria et al (2013) in Hawassa town of Ethiopia and Pearson et al (2002) in central Ethiopia. Poor body condition score is an indicator of less body fat. Thin donkeys have less natural padding that protects them from friction, pressure and lesion caused by harnessing, and below score 3 in BCS is correlated with lesions of skin (Pritchard et al., 2005). Animals with poor body condition are more prone to dehydration and decrease the elasticity of the skin and the prominence of bones leading to easy skin injury (Kumar et al., 2014).

The present finding revealed that age had significant effect $(p<0.05)$ on prevalence of wound. The older donkeys were seen much more affected than the younger ones. Tesfaye et al (2016), Kumar et al (2014) and Biffa and Woldemeskel (2006) also reported similar findings in their studies on working donkeys in different parts of Ethiopia. Generally old animals have more exposure to work and carrying heavy load over a long distance. Also, prolonged and frequent exposure of working animals in working lifetime, less owners' attention to wound management and the immune defense mechanism of an animal also reduce with age advancement (Kumar et al., 2014). 
Duration of work and average weight loaded were also significantly $(p<0.05)$ associated with the occurrence of wound in working donkeys. Generally, a donkey should not carry more than one third of its body weight (Pearson et al., 2003). Overloading and overworking are the predisposing factors for the occurrence of wound (Julia, 2016). Biffa and Woldemeskel (2006) have also reported external injuries due to overwork and overload. Sells et al (2010) and Pritchard et al (2005) reported that when donkeys are carrying heavy load for long distance without sufficient rest, it leads to a higher prevalence of wound due to persistent irritation and reduce their body condition score.

Results of questionnaire survey showed that majority of owners were not having knowledge on donkey welfare issues. Vaccination and deworming are practiced mainly by those farmers who are living near urban areas and have access to veterinary services. Majority (40.8\%) of sick donkeys were treated by traditional healers. Tesfaye et al (2016) reported that $48.3 \%$ of sick donkeys were taken to nearby veterinary clinic, $35.8 \%$ provide house medication (Treat with the medicinal plant) and $15.8 \%$ do nothing while Kumar et al (2014) reported that $31.6 \%$ of the sick donkeys were taken to the nearby veterinary clinics, $10.5 \%$ were treated traditionally, $57.9 \%$ did not get any help from their owner and forced to work regardless of the disease. Mohammed (1991) reported that low numbers of donkeys in Ethiopia were taken to the clinic compared to other domestic animals annually and when the donkeys are critically sick, often they were given a number of traditional treatments first. There are many constraints reported by the donkey owners in the study area. Among the major constraints; financial shortage, high price or unavailability of drug, disease, lack of veterinary services and nutritional constraints were commonly reported. Generally, the donkey owners are resource poor farmers and they often lack financial means to provide their donkeys with proper care (Pearson and Krecek, 2006). Diseases and lack of veterinary services as constraints for keeping donkeys were also reported by Kumar et al (2014).

\section{Conclusion}

Donkeys are important animals providing traction power, transport services at low cost and source of income generation for resource poor farmers in the study area. But the welfare issues were the major problems encountered in working donkeys. Poor body condition, skin abnormality and presence of various types of wound, parasitic and behavioral problems were the major constraints identi- 
fied in this study area which shows lack of owner's awareness towards nutrition, veterinary care and welfare practices. Creation of awareness on welfare issues among the donkey owners through extension activities is recommended.

\section{Conflict of interest}

The authors declare that there is no conflict of interest.

\section{References}

Ahmed, S., Muhammad, G., Saleem, M. and Rashid, I., 2010. Comparative aspects of prevalence and chemotherapy of ecto-parasite, endo-parasite and blood parasites of draught equines in Faisalabad metropolis Pakistan. The Brooke (educations.): The Proceedings of the $6^{\text {th }}$ International conference of improving the welfare in working equines held at the India Habitat Centre, New Delhi. The Brooke, 30 Farringdon Street, London, EC4A4HH: UK, Pp. 262-265.

Bekele, M., Gebremichael, B., Teshome, M., Zeleke, W., Goshu, D., Mengesha, T.,Tesfaye, A. and Mesfin, D., 2013. Assessment of human aspect regarding the welfare of cart horses: perspective of Jimma town, south west Ethiopia. Res. J. Vet. Sci., 6(1), 1-12.

Biffa,D.and Woldemeskel, M., 2006. Causes and Factors Associated with Occurrence of External Injuries in Working Equines in Ethiopia. The Int. J. Appl. Res. Vet. Med., 4(3), 1-7.

Biswas, P., Dutt, T., Patel, M., Kamal, R., Bharti, K. and Sahu, S., 2013. Assessment of pack animal welfare in of and around Bareilly city of India. Vet. World, 6(6), 332-336.

Burn, C., Dennison, L. and Whay, R., 2010. Environmental and demographic risk factors for poor welfare in working horses, donkeys and mules in developing countries. The Vet. J. 186(4), 385-392.

Burn, C., Pritchard, J., Farajat, M., Twaissi, A. and Whay, R., 2007. Risk factors for strap related lesions in working donkeys at the World Heritage Site of Petra in Jordan. The Vet. J., 178(2), 263-271.

Crane, M., 1997. Medical. In: Svendsen, E. (edition): The professional hand book of the Donkey, 3rd Education. Whittet Books LTD, W140By, London, Pp. 29.

CSA, 2014/15. Agricultural sample survey. Report on livestock and livestock characteristics. The Federal Democratic Republic of Ethiopia, Central Statistical Agency 
(CSA). Private Peasant Holdings. Statistical Bulletin 578, Addis Ababa, Ethiopia, April 2015.

Curran, M., Gebreab,F. and Smith, D., 2005. The impact of access to animal health services on donkey health and livelihoods in Ethiopia. Trop. Anim. Hlth. Prod., 37(1), 47-65.

Gbrewold, A., Tegene A. and Yami, A.,1997. Donkeys, people and development: research needs of donkey utilization in Ethiopia, in: Fielding, D. and Starkey, P. (Educations). Donkeys, People and Development.A resource book in the Animal Traction Network for Eastern and Southern Africa (ATNESA). ACP-EU Technical Centre for Agricultural and Rural Cooperation (CTA).

Herago, T., Megersa, M., Niguse, A. and Feyera, T., 2015. Assessment on Working Donkey Welfare Issue in WolaitaSoddoZuria District, Southern Ethiopia, Global Vet., 14(6), 867-875.

Julia, B., 2016. Assessment of donkeys' welfare in Addis Ababa and Ambo, Ethiopia. Master thesis Animal Science. Faculty of Veterinary Medicine and Animal Science. Swedish University of Agricultural Sciences.

Kumar, N., Fisseha, K., Shishay, N. and Hagos, Y., 2014. Welfare assessment of working donkeys in Mekelle city, Ethiopia. Global Vet., 12(3), 314-319.

Mekuria, S. and Abebe, R., 2010. Observation on major welfare problems of equine in Meskan district, southern Ethiopia. Livesto. Res. Rural Dev., 22(3),70-73.

Mekuria, S., Mulachew, M. and Abebe, R., 2013. Management practices and welfare problems encountered on working equids in Hawassa town, Southern Ethiopia. J. Vet. Med. Anim. Hlth., 5(9), 243-250.

Mohammed, A.,1991. Management and breeding aspects of donkeys around Awassa, Ethiopia. In: Fielding, D. and Pearson, R.A. (editions.): Donkeys, Mules and Horses in Tropical Agricultural Development. CTVM: Edinburgh UK, Pp. 185-188.

Morgan, R., 2008. The epidemiology of lameness in working donkeys in Addis Ababa and the central Oromia region of Ethiopia: a comparative study of urban and rural donkey populations. Colloquium Proceed., 8(3), 99-106.

Morka,A., Hunde, A., Endebu, B., Hirpa, E. and Mamo, B., 2014. Health and Welfare Assessment of Working Equine in and Around Nekemte Town, East Wollega Zone, Ethiopia. American-Eurasian J. Sci. Res., 9(6), 163-174.

NAWC, (National Animal Welfare Council), 2005. Equine industry welfare guideline compendium for horse ponies and donkey, 2nd edition. Body Condition Scoring for horse and donkey: Pp. 82-95. 
Pearson, A. and Krecek, R., 2006. Delivery of health and husbandry improvements to working animals in Africa. Trop. Anim. Hlth. Prod., 38(2), 93-101.

Pearson, R., Mengistu, A., Agajie, F., Allanand, G. and Smith, M., 2002. Use and management of donkeys in Peri-Urban areas of Ethiopia: Cent.Trop. Vet. Med., 5(7), 9-13.

Pearson, R., Simalenga, T. and Krecek, R., 2003. Harnessing and hitching donkey, mules and horses for work. Center for Tropical veterinary Medicine, University of Edinburgh, Pp. 34.

Pritchard, J., Lindberg, C., Main, J. and Whay, R., 2005. Assessment of the welfare of working horses, mules and donkeys, using health and behavior parameters. Prev. Vet. Med., 69(4), 265-283.

Rushen, J., Tayler, A. and de Passille, M., 1999. Domestic animals' fear of humans and its effect on their welfare. Appl. Anim. Behavior Sci., 65(3), 285-303.

Sameeh, M., Dirar, M., Zain, H. and Sarah, F., 2014.Equine Diseases and Welfare in Jordan: A Retrospective Study (1261 cases). Jordan J. Agri. Sci.,10(3), 21-24.

Sells, P., Pinchbeck, G., Mezzane, H., Ibourki, J. and Crane, M., 2010. Pack wounds of donkeys and mules: In the Northern high atlas and lowlands of Morocco. Equine Vet. J., 42(3), 219-226.

Smith, D., 2014. Use and management of donkeys by poor societies in peri-urban areas in Ethiopia. Food and Agriculture Organization - FAO. 2006. Ethiopia.

Starkey, P., 1998. Improving donkey utilization and management. DebreZeit, Ethiopia. ATNESA Publication. Report of the international ATNESA workshop held 5-9 May 1997, DebreZeit, Ethiopia.

Swann, W. J., 2006. Improving the welfare of working equine in developing countries; Appl. Anim. Behavior Sci., 100(2), 148-151.

Tesfaye, S., Deressa, B., and Teshome, E.,2016. Study on the Health and Welfare of Working Donkeys in Mirab Abaya District, Southern Ethiopia. Acad. J. Anim. Dis., 5(2), 40-52.

Thrusfield, M., 1995.Veterinary Epidemiology $2^{\text {nd }}$ Education. Department of veterinary clinical studies, Royal Duch School of Veterinary Studies, University of Eden burgh. Publishing Blackwell Wissen Chaft Velag, Berlin Germany. 